\title{
Differential expression profiling of the early response to Ustilaginoidea virens between false smut resistant and susceptible rice varieties
}

Yanqing Han ${ }^{1,2 \dagger}$, Kang Zhang ${ }^{1,2 \dagger}$, Jun Yang ${ }^{1,2}$, Nan Zhang ${ }^{1,2}$, Anfei Fang ${ }^{1,2}$, Yong Zhang ${ }^{1,2}$, Yongfeng Liu ${ }^{3}$, Zhiyi Chen ${ }^{3}$ Tom Hsiang ${ }^{4}$ and Wenxian Sun ${ }^{1,2^{*}}$

\begin{abstract}
Background: Rice false smut caused by Ustilaginoidea virens has recently become one of the most devastating rice diseases worldwide. Breeding and deployment of resistant varieties is considered as the most effective strategy to control this disease. However, little is known about the genes and molecular mechanisms underlying rice resistance against $U$. virens.

Results: To explore genetic basis of rice resistance to U. virens, differential expression profiles in resistant 'IR28' and susceptible 'LYP9' cultivars during early stages of $U$. virens infection were compared using RNA-Seq data. The analyses revealed that 748 genes were up-regulated only in the resistant variety and 438 genes showed opposite expression patterns between the two genotypes. The genes encoding receptor-like kinases and cytoplasmic kinases were highly enriched in this pool of oppositely expressed genes. Many pathogenesis-related $(P R)$ and diterpene phytoalexin biosynthetic genes were specifically induced in the resistant variety. Interestingly, the RY repeat motif was significantly more abundant in the $5^{\prime}$-regulatory regions of these differentially regulated $P R$ genes. Several WRKY transcription factors were also differentially regulated in the two genotypes, which is consistent with our finding that the cis-regulatory W-boxes were abundant in the promoter regions of up-regulated genes in IR28. Furthermore, $U$. virens genes that are relevant to fungal reproduction and pathogenicity were found to be suppressed in the resistant cultivar.

Conclusion: Our results indicate that rice resistance to false smut may be attributable to plant perception of pathogen-associated molecular patterns, activation of resistance signaling pathways, induced production of PR proteins and diterpene phytoalexins, and suppression of pathogenicity genes in U. virens as well.
\end{abstract}

Keywords: Differential expression profiling, Protein kinases, Pathogenesis-related genes, Phytoalexins, Resistance, Rice false smut, Ustilaginoidea virens

\footnotetext{
* Correspondence: wxs@cau.edu.cn

${ }^{\dagger}$ Equal contributors

'Department of Plant Pathology, China Agricultural University, 2 West

Yuanmingyuan Rd., Haidian District, Beijing 100193, China

${ }^{2}$ Key Laboratory of Plant Pathology, Ministry of Agriculture, China Agricultural

University, Beijing 100193, China

Full list of author information is available at the end of the article
}

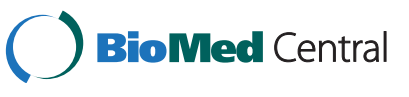

(c) 2015 Han et al. Open Access This article is distributed under the terms of the Creative Commons Attribution 4.0 International License (http://creativecommons.org/licenses/by/4.0/), which permits unrestricted use, distribution, and reproduction in any medium, provided you give appropriate credit to the original author(s) and the source, provide a link to the Creative Commons license, and indicate if changes were made. The Creative Commons Public Domain Dedication waiver (http://creativecommons.org/publicdomain/zero/1.0/) applies to the data made available in this article, unless otherwise stated. 


\section{Background}

Rice false smut (RFS) caused by the Clavicipitaceous fungus Ustilaginoidea virens, also known as Villosiclava virens, has recently become one of the most devastating grain diseases in the majority of rice-planting regions worldwide [1]. RFS was first reported in Tirunelveli district of Tamil Nadu State of India and previously categorized as a minor disease due to its sporadic occurrence [2]. However, the disease has expanded rapidly in China due to large-scale planting of high-yield rice cultivars and hybrids, heavy application of nitrogenous fertilizer and global warming in the past two decades, and has been found in about one third of rice cultivation areas in severe years $[1,3]$. RFS outbreaks have also been reported in some American, Italian and Southern Asian rice-growing regions [4]. The disease incidence rate was estimated to be $15.85 \%$ in 2011 across northern India, and the smut balls formed on up to 100 grains per panicle in some fields with high disease severity [5].

Aside from huge yield losses (up to $40 \%$ in severe years) caused by RFS, $U$. virens produces abundant amounts of mycotoxins that often contaminate rice products and are poisonous to both human and animals [6-8]. Due to the economic importance of the disease, many studies have been performed on the occurrence, pathogen detection, mycotoxin identification, infection lifecycle and chemical control of the disease [4, 9-12]. However, research on screening of rice germplasm for RFS resistance, molecular mechanisms underlying RFS resistance and the pathogenicity of $U$. virens is scarce [13]. Breeding for rice cultivars with durable resistance to RFS is considered to be one of the most economical, environmentally safe and effective strategies for disease management. A rapid and effective inoculation method has been developed to evaluate rice resistance to $U$. virens and screen resistant germplasm for breeding $[14,15]$. Although no rice variety has yet been identified to have complete or high level of resistance, cultivars do exhibit significant differences in quantitative resistance to $U$. virens $[16,17]$. Much effort has been taken to identify quantitative trait loci (QTL) associated with rice resistance to $U$. virens [17-19]. It was reported that the rice cultivar IR28 has a relatively high resistance to RFS, which was controlled by two major and multiple minor resistance genes [17]. Eight QTLs controlling RFS resistance were also found in the resistant rice variety Lemont [19]. However, no QTL for RFS resistance in rice has yet been isolated and resistance mechanisms are largely unknown [17].

In plants, multiple strategies have evolved to recognize pathogens and thus trigger immune systems to defend against pathogen invasion. Recognition of conserved pathogen-associated molecular patterns (PAMPs) by pattern recognition receptors (PRRs) activates PAMP- triggered immunity (PTI) and prevents further colonization on the hosts by microbial pathogens [20]. Perception of pathogen effectors by intercellular $\mathrm{R}$ proteins in plants activates effector-triggered immunity (ETI), which includes rapid and acute cell death responses in plants and restricts multiplication of pathogens [21]. Furthermore, systemic acquired resistance (SAR) induced by the signal molecule salicylic acid (SA) may confer long-lasting protection against a wide range of pathogens [22].

Pathogenesis-related $(P R)$ genes are often induced in plant defense signaling through the action of plant hormones including salicylic acid, jasmonic acid or ethylene [23]. In Arabidopsis, expression of PR1, PR2 and PR5 is induced by SA and used as a signature for SAR [24]. These induced PR proteins possess antimicrobial activities through their hydrolytic, proteinase-inhibitory and membrane-permeabilizing abilities, or serve as defense signals [22, 23]. As an example, PR-2 proteins function as $\beta$-1,3-glucanases that catalyze the hydrolytic cleavage of 1,3- $\beta$-D-glucosidic linkages in $\beta$-1,3-glucans present in the fungal cell walls. The disrupted cell walls cause cell lysis and death in fungi [25]. The PR-3 proteins possess endo-chitinase activities and retard fungal growth by the enzymatic hydrolysis of chitin, the predominant constituent of fungal cell walls. The released chitin fragments often act as endogenous triggers to stimulate plant defenses [26]. Peroxidases (PR-9) are heme-containing glycoproteins that participate in a number of physiological processes, such as biosynthesis of ethylene, suberization and lignification of plant cells in response to pathogen infection, wounding and abiotic stresses [27, 28].

Comprehensive transcriptome analyses during the interaction of plants and pathogens are commonly used to provide new insights into molecular mechanisms of plant resistance. Transcriptome comparisons between durable resistant and susceptible rice varieties in response to attack by the blast fungus Magnaporthe ory$z a e$ revealed that chitin-oligosaccharide sensing factors, wall-associated kinases, MAPK cascades and WRKY transcription factors were involved in rice blast resistance [29]. In addition, gene expression profiling of rice in response to the infection of rice stripe virus (RSV) and small brown plant-hopper (SBPH) revealed by transcriptome analyses indicated that the jasmonate signaling pathway was important in rice resistance to SBPHs [30]. Transcriptome analyses were also performed for other host-pathogen interaction through RNA-Seq, including wheat and Fusarium graminearum [31], maize and Sporisorium reilianum f. sp. zeae [32], cotton and the wilt fungus Verticillium dahliae [33], soybean and Xanthomonas axonopodis pv. glycines [34], banana and F. oxysporum f. sp. cubense [35]. Many genes were thereby revealed to be involved in resistance-associated signal transduction and defense mechanism in plants. 
For example, $P R$ genes were found to be significantly up-regulated in rice after blast fungus inoculation [36] and in the maize resistant variety Mo17 in response to S. reilianum f. sp. zeae [32].

Recently, RNA-Seq has been used to reveal stage-specific biological processes related to the compatible rice- $U$. virens interaction and expression profiling in rice varieties at the late stage of $U$. virens infection [37, 38]. It was reported that the primary site of $U$. virens colonization was at the base of the filaments with the inner spikelets becoming infected by hyphae at $24 \mathrm{~h}$ post inoculation (hpi) [39]. Here, we analyzed and compared gene expression profiles of the RFS resistant variety IR28 and susceptible LYP9 after $U$. virens inoculation at early stages (24 hpi and $48 \mathrm{hpi}$ ) using transcriptome data. The results indicate that several major gene families might be involved in rice resistance to $U$. virens infection, including receptor-like kinases, $P R$ genes, diterpene phytoalexin biosynthesis genes and WRKY transcription factors. These results provide important information to further understand molecular mechanisms of rice reaction and resistance to false smut.

\section{Results}

Disease symptoms of false smut in rice cultivars IR28 and LYP9

To confirm RFS resistance or susceptibility of IR28 and LYP9, disease symptoms were observed on the panicles inoculated with different $U$. virens isolates. Infected grains per inoculated spikelet of the cultivars IR28 and LYP9 were counted (Table 1 and Additional file 1: Figure S1). In general, more false smut balls were produced on LYP9 panicles than those on IR28 panicles for each of three isolates. The average number of false smut balls per panicle formed on LYP9 $(26.2 \pm 2.40)$ was significantly more than that on IR28 ( $5.75 \pm 0.74)$ after P1 inoculation. The number of false smut balls produced on both cultivars inoculated with $37-1$ and $39-3$ was less than that formed on the panicles after P1 inoculation. These data confirm that the cultivar IR28 is much more resistant to $U$. virens than LYP9. The results also indicate that virulence to both rice cultivars of the isolates $37-1$ and $39-3$ is much less than that of P1. Therefore, the P1 isolate was chosen for inoculation in further expression profiling analyses.

\section{RNA-Seq data and aligning to the reference genomes}

Changes in gene expression level of rice cultivars IR28 and LYP9 at $24 \mathrm{~h}$ and $48 \mathrm{~h}$ after P1 inoculation were analyzed using RNA-Seq data. A total of 64.4 million clean reads, each of which was $49 \mathrm{bp}$ in length, were generated from eight cDNA libraries (the susceptible cultivar LYP9 and resistant cultivar IR28 at 24 and $48 \mathrm{hpi}$ and four mock-inoculated controls). About $82 \%$ of the clean reads were successfully aligned to the Oryza sativa L. spp. indica reference genome (Additional file 2: Table S1). Saturation analysis showed that newly emerging tags were gradually reduced as the total number of sequence tags increased, and the detectable tags approached saturation when the number of sequencing tags reached $\sim 3$ million (Additional file 3: Figure S2). These results indicate that the gene transcript data were reliable, and suitable for further transcriptome analysis.

\section{Expression profiling analyses in resistant and susceptible cultivars in response to $U$. virens inoculation}

To uncover the genes that might be involved in RFS resistance, all differentially expressed genes (DEGs) were identified in IR28 and LYP9 at $24 \mathrm{~h}$ and $48 \mathrm{~h}$ after P1 inoculation as compared with mock-inoculated samples. Venn diagrams were then drawn to show DEGs that were common to both rice genotypes IR28 and LYP9, or specific to either cultivar in response to P1 inoculation (Fig. 1a). A total of 1072 DEGs were identified in IR28 at $24 \mathrm{hpi}$, among which 94 were IR28specific, 205 were common to IR28 and LYP9, and 773 were DEGs only in IR28 but were expressed (non-DEG) in LYP9. In contrast, 1590 DEGs were identified in LYP9 including 51 LYP9-specific and 1334 were DEGs only in LYP9 but expressed in IR28. Meanwhile, 1190 and 1790 DEGs were identified in IR28 and LYP9 at 48 hpi, respectively. Among them, 389 were identified as DEGs common to IR28 and LYP9, and 786 were categorized as DEGs only in IR28 but expressed in LYP9; 75 were LYP9-specific, and 1326 were found as DEGs only in LYP9 but expressed in IR28. Among common

Table 1 Virulence assays of three U. virens isolates (37-1, 39-3 and P1) to the varieties IR28 and LYP9, showing that IR28 is significantly more resistant to $U$. virens infection than LYP9

\begin{tabular}{|c|c|c|c|c|c|}
\hline \multirow[t]{2}{*}{ Isolates } & \multicolumn{2}{|c|}{ Infected panicle rate } & \multicolumn{2}{|c|}{ False smut balls per panicle } & \multirow[t]{2}{*}{$P_{\text {_value }}$} \\
\hline & IR28 & LYP9 & IR28 & LYP9 & \\
\hline Mock & $0 \%(n=20)$ & $0 \%(n=20)$ & 0 & 0 & \\
\hline $37-1$ & $20 \%(n=20)$ & $50 \%(n=20)$ & $0.45 \pm 0.23$ & $1.05 \pm 0.30$ & 0.03525 \\
\hline $39-3$ & $90 \%(n=20)$ & $95 \%(n=20)$ & $1.05 \pm 0.20$ & $4.80 \pm 0.65$ & $3.34 \mathrm{E}-05$ \\
\hline P1 & $100 \%(n=20)$ & $100 \%(n=15)$ & $5.75 \pm 0.74$ & $26.2 \pm 2.40$ & 1.43E-07 \\
\hline
\end{tabular}

$n$ stands for the number of panicles 
A
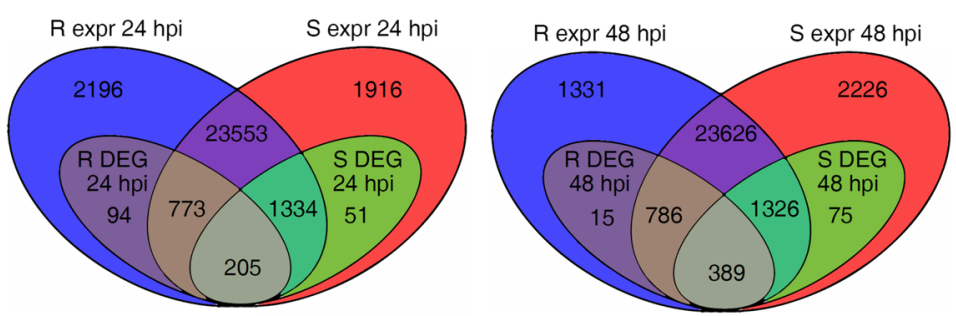

B
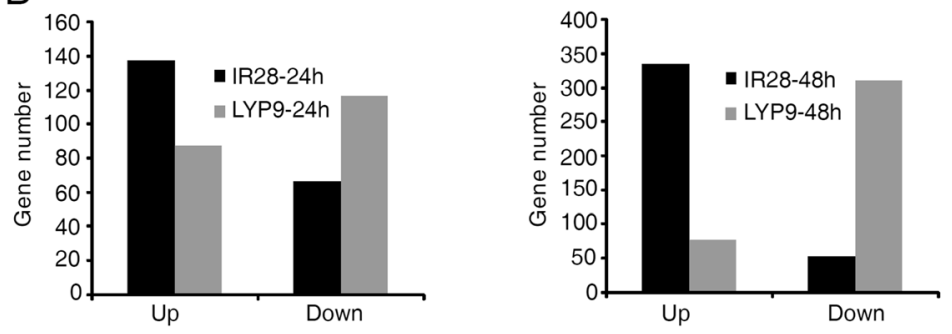

Fig. 1 Venn diagrams of all differentially expressed genes in the resistant variety IR28 and susceptible variety LYP9 in the early stages of U. virens infection. a The expressed genes (expr) and differentially expressed genes (DEGs) in IR28 (R) and LYP9 (S) at 24 hpi and 48 hpi. A total of 205 DEGs were common in IR28 and LYP9 at 24 hpi while 389 DEGs were common at 48 hpi. b Up-regulated and down-regulated genes among common DEGs in IR28 and LYP9 at $24 \mathrm{hpi}$ and 48 hpi. Among common DEGs, more DEGs were up-regulated in IR28 while more DEGs were down-regulated in LYP9

DEGs shared by both cultivars at $24 \mathrm{hpi}$, more genes were up-regulated in IR28 (138) than in LYP9 (88) while fewer DEGs (67) in IR28 were down-regulated than those (117) in LYP9. Among 389 common DEGs at $48 \mathrm{hpi}$, more (335) were up-regulated compared with down-regulated ones (54) in IR28, while many more genes (311) were suppressed than transcriptionally induced genes (78) in LYP9 at this infection stage (Fig. 1b). Interestingly, the majority of common DEGs (438) exhibited opposite expression patterns between the resistant and susceptible varieties after P1 inoculation, suggesting that defense responses are distinctively different between the two varieties in response to $U$. virens infection. We speculate that the IR28-specific DEGs and common DEGs which were up-regulated in IR28 and down-regulated in LYP9 might be involving in RFS resistance (Additional file 4: Table S2).

\section{Comparison between transcriptomes of IR28 and LYP9 in response to $U$. virens infection by cluster analysis}

A total of 3847 DEGs in IR28 and in LYP9 were classified through cluster analysis. The heat map generated by cluster analysis showed that the majority of DEGs have similar expression patterns between two different time points in the same cultivar. The analysis also showed that these DEGs can be categorized into four major groups: genes down-regulated in both IR28 and LYP9 (group I); genes up-regulated in IR28 while downregulated in LYP9 (group II); genes up-regulated in both IR28 and LYP9 (group III); and genes up-regulated in
LYP9 while suppressed in IR28 (group IV) (Fig. 2). It was speculated that the genes specifically up-regulated in IR28 may play important roles in RFS resistance.

\section{Gene ontology enrichment analysis}

To investigate functions or biological processes that the differentially regulated genes might be involved in, gene ontology (GO) enrichment analysis was performed to classify up-regulated DEGs (Additional file 5: Table S3). Within three major GO categories (cellular components, molecular functions and biological processes), 14 common GO terms, 2 IR28-specific and 31 LYP9-specific GO terms were enriched at $24 \mathrm{hpi}$, while 12 common GO, 1 IR28-specific and 30 LYP9-specific GO terms were enriched at $48 \mathrm{hpi}$. The gene names in the GO terms enriched specifically by IR28 were searched for items that might be related to RFS resistance. Among them, the GO term "transferase activity" was the only one that was significantly enriched $(P \leq 0.05)$ in IR28 at both inoculation time points. It is most likely that some genes with transferase activity are involved in RFS resistance (Additional file 6: Figure S3).

\section{Some protein kinases including receptor-like kinases are likely involved in RFS resistance}

The 142 DEGs in IR28 that were categorized into the GO term "transferase activity" were subject to Pfam domain searches. The results showed that the majority of these DEGs belonged to two gene families encoding protein kinases and glutathione $\mathrm{S}$ transferases 


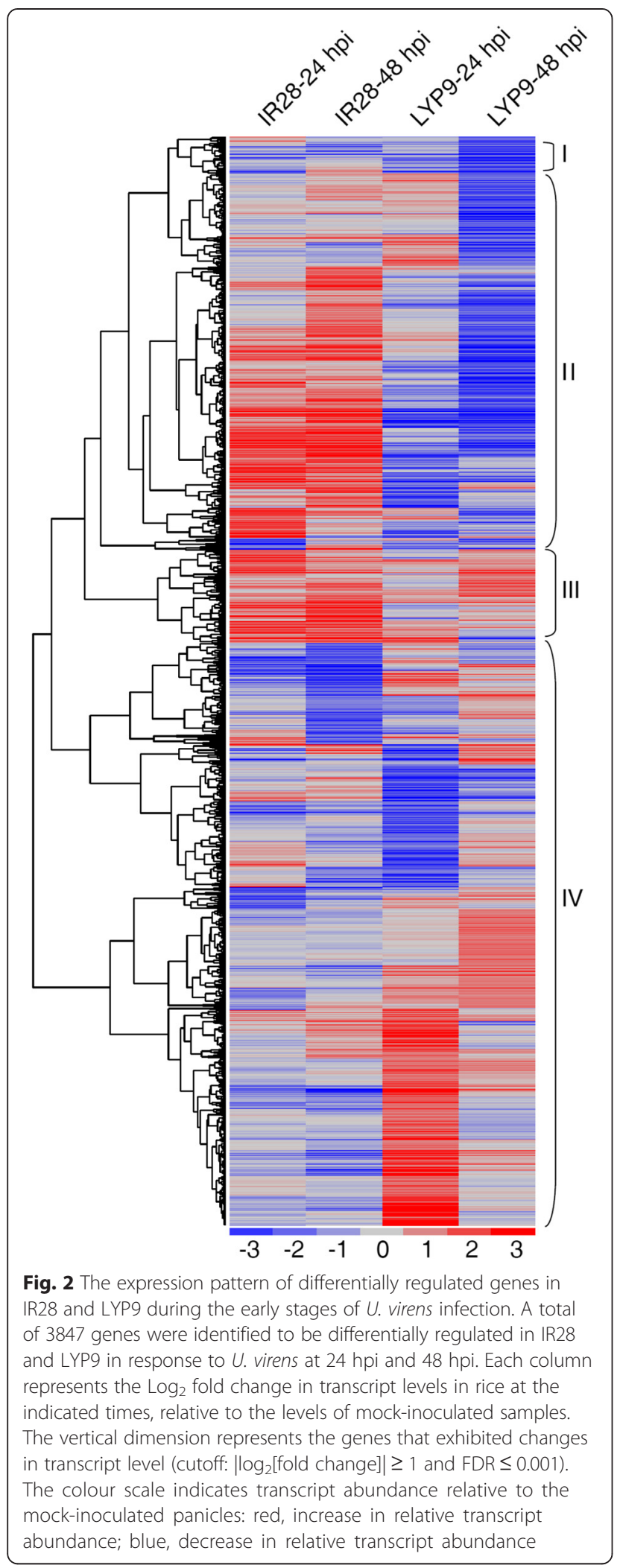

(Additional file 7: Table S4). Comparison of gene expression levels between the resistant and susceptible cultivars showed that expression of glutathione $S$ transferases was not significantly different between IR28 and LYP9. In contrast, the differentially-regulated protein kinases exhibited distinctive expression patterns between the two cultivars (Additional file 6: Figure S3). Twentyeight and 35 protein kinase genes were induced in IR28 at 24 hpi and 48 hpi, respectively (Fig. 3). Notably, 11 protein kinase genes were up-regulated at both inoculation time points. All of the induced protein kinase genes in IR28 at 24 hpi except BGIOSGA00144 were transcriptionally suppressed in LYP9. Meanwhile, the up-regulated kinase genes at $48 \mathrm{hpi}$ in IR28 except BGIOSGA010192 and BGIOSGA017269 were also down-regulated in LYP9 (Fig. 3). These differentially regulated kinases were classified into four groups, B-lectin receptor-like kinases, leucine-rich repeat (LRR) receptor-like kinases, LysM domain-containing receptor kinases and cytoplasmic kinases (Fig. 3). In particular, a B-lectin receptor kinase gene (BGIOSGA024885) was dramatically induced at both time points. Another B-lectin receptor kinase gene (BGIOSGA034733) and a protein kinase gene (BGIOSGA010552) were found to be greatly upregulated with 239- and 306-fold expression in IR28 at $24 \mathrm{hpi}$ and $48 \mathrm{hpi}$, respectively. Divergent patterns of expression in the resistant and susceptible cultivars strongly suggest that these kinase-encoding genes might be essential for rice resistance to RFS in IR28.

\section{Expression profiles of pathogenesis-related genes}

To identify other important genes that might be involved in biosynthetic or signaling pathways critical for RFS resistance in IR28, pathway enrichment analyses were performed using KEGG (Additional file 8: Table S5). Only a few defense-associated biosynthetic pathways involving diterpenoid, cutin, suberine or wax were enriched in the transcriptome of the resistant cultivar, while more pathways, such as phenylalanine metabolism and secondary metabolite biosynthesis, were significantly enriched in both rice genotypes after inoculation. Comparisons of expression levels of DEGs in these enriched pathways revealed that many genes were upregulated in the resistant cultivar, while down-regulated in the susceptible LYP9. Among them, multiple gene families encoding PR proteins were greatly up-regulated after P1 inoculation in IR28 (Fig. 4).

Five $\beta$-1,3-glucanase genes belonging to the PR2 family exhibited significantly different expression patterns between IR28 and LYP9 after P1 inoculation (Additional file 9: Table S6). In IR28, these genes were transcriptionally induced at $24 \mathrm{hpi}$ and upregulated even more dramatically at $48 \mathrm{hpi}$. In contrast, these genes were generally suppressed or not 
A

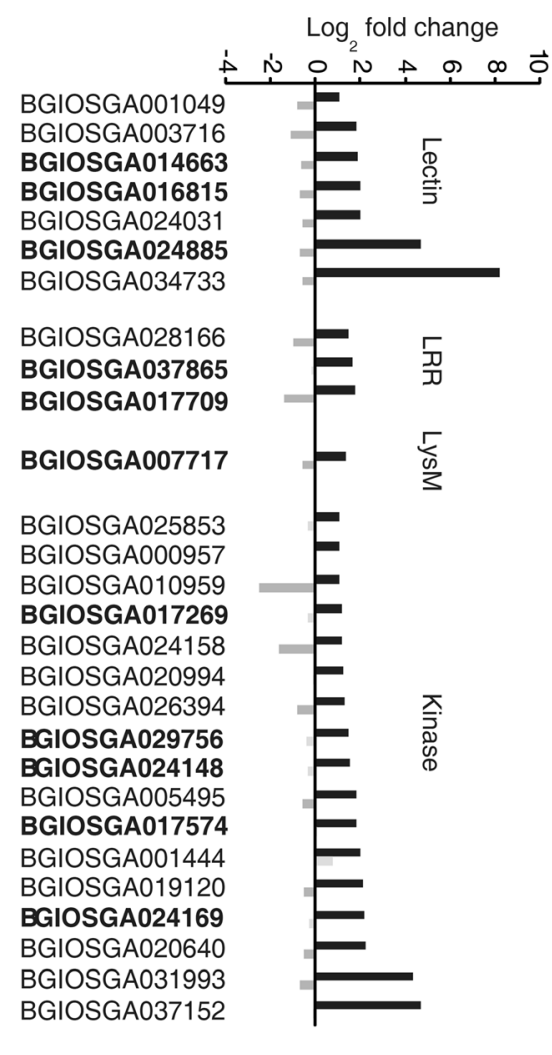

B

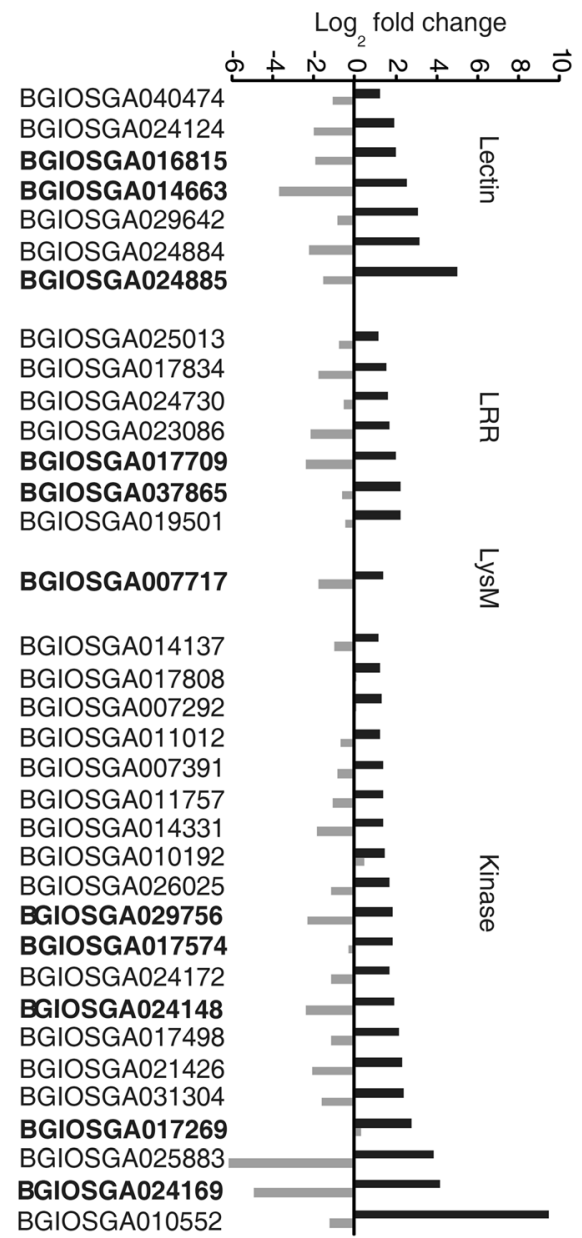

Fig. 3 The protein kinase genes exhibiting opposite expression patterns between IR28 and LYP9 in response to U. virens infection. A total of 28 and 35 protein kinase genes were identified to have opposite expression patterns between the two genotypes at 24 hpi (a) and 48 hpi (b). Bold fonts indicate the protein kinase genes that have a consistent expression pattern between two inoculation time points. Lectin, LRR, LysM and kinase indicate lectin-receptor like kinases, leucine-rich repeat containing receptor-like kinases and lysin motif-containing receptor-like kinases and cytoplasmic kinases, respectively

significantly regulated at both time points in LYP9. Extensive transcriptome analyses in both cultivars also showed that three class I (PR3), two class II (PR4) and 13 class III chitinase genes (PR8) were up-regulated at $24 \mathrm{hpi}$ and 48 hpi in IR28, while these genes were generally down-regulated at the two time points in LYP9 (Fig. 4 and Additional file 9: Table S6). It is interesting to note that genes BGIOSGA035717 to 21, BGIOSGA033526, BGIOSGA033527, BGIOSGA033529 and BGIOSGA033530 were tandemly arranged in a chitinase gene cluster on chromosome 11 . In addition, 16 peroxidase genes (PR9), 3 thaumatin-like genes (PR5) and 5 proteinase inhibitor genes (PR6) were identified as being induced in IR28 while most were inhibited in LYP9 after P1 inoculation. Phenylalanine ammonia-lyases (PALs), sometimes classified as PR proteins, are involved in the synthesis of both phytoalexins and lignin, to inhibit pathogens from penetrating cell walls [40]. Three PAL genes (BGIOSGA014703, BGIOSGA018017 and BGIOSGA005998) involved in the phenylalanine metabolism and phenylpropanoid biosynthesis pathways were also up-regulated only in IR28 (Fig. 4 and Additional file 9: Table S6). Taken together, our finding that many defenserelated genes including $P R$ and $P A L$ genes showed opposite expression patterns between IR28 and LYP9 after $U$. virens inoculation indicates that these genes play essential roles in RFS resistance in IR28.

\section{Diterpene phytoalexin biosynthesis genes}

A total of 15 phytoalexins (PAs) have been characterized in rice, including 14 diterpenoid PAs and one flavonoid PA, sakuranetin [41, 42]. The diterpenoid 


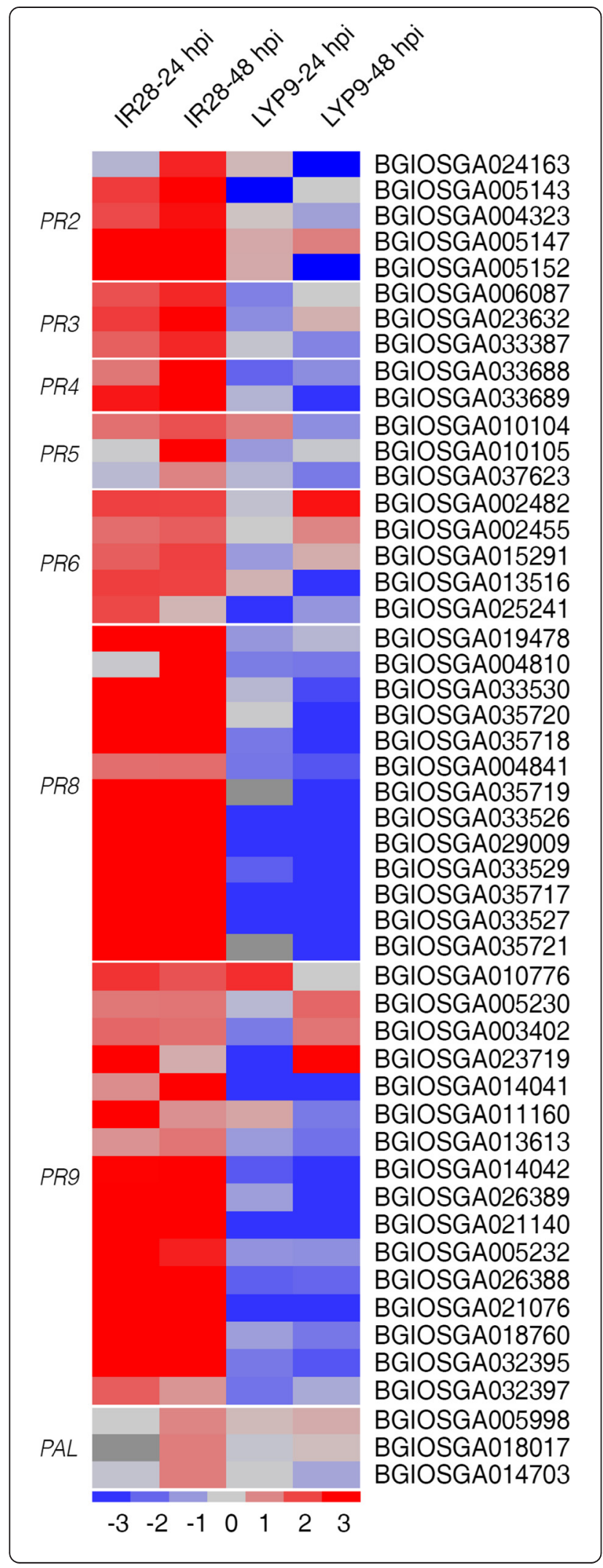

Fig. 4 Heat maps showing expression patterns of pathogenesis-related and PAL genes that were identified to be differentially regulated in IR28 and LYP9. The technical details and the colour scale are the same as those in Fig. 2

PAs in rice have been categorized into four distinct types: phytocassanes $\mathrm{A}$ to $\mathrm{E}$, oryzalexins $\mathrm{A}$ to $\mathrm{F}$, momilactones A and B, and oryzalexin S [43]. Many essential genes involved in phytoalexin biosynthesis pathways were previously identified (Fig. 5). Among them, seven genes were significantly up-regulated in IR28 at $24 \mathrm{hpi}$ and $48 \mathrm{hpi}$, and enriched specifically in DEGs of the resistant cultivar revealed by KEGG pathway enrichment analyses. These genes included OsCPS2 (BGIOSGA008469) which is involved in the phytocassane A-E synthesis, OsCPS4 (BGIOSGA015502), CYP99A2 (BGIOSGA015504), CYP99A3 (BGIOSGA015 981), and OsMAS (BGIOSGA038038) which are involved in the biosynthesis of momilactone $\mathrm{A}$ and $\mathrm{B}$, CYP76M7 (BGIOSGA008466) that catalyzes the biosynthesis of oyzalexin A-F, and OsKSL11 (BGIOSGA034012) (Fig. 5 and Additional file 10: Table S7). Up-regulation of these phytoalexin biosynthesis genes in response to $U$. virens indicates that phytoalexins are important components in rice resistance to RFS.

\section{Differential expression of WRKY transcription factors}

WRKY transcription factors are one of the largest protein superfamilies in plants that can regulate various defense processes and play important roles in controlling the transcription of defense-related genes through binding to W-boxes in their promoters, a key cis-element in defense-related transcriptional regulation $[44,45]$. Here, we identified 13 WRKY genes that were differentially expressed in IR28 and LYP9 after P1 inoculation (Fig. 6 and Additional file 11: Table S8). In IR28, five WRKY transcription factors were found to be significantly up-regulated. Among them, OsWRKY53, OsWRKY69 and OsWRKY71 genes were induced at both time points in IR28 and significantly inhibited at $48 \mathrm{hpi}$ in LYP9, suggesting that these WRKY proteins might function as key positive regulators in the rice defense against the infection by $U$. virens during initial colonization.

\section{The cis-acting regulatory element analysis}

Venn diagrams in Additional file 12: Figure S4 showed up-regulated and down-regulated DEGs with consistent expression patterns at both time points in IR28 and LYP9 in response to P1 inoculation. In IR28, 454 genes exhibited similar expression patterns between $24 \mathrm{hpi}$ and 48 hpi, including 284 induced and 170 suppressed genes. In susceptible LYP9, 67 genes were up-regulated and 136 


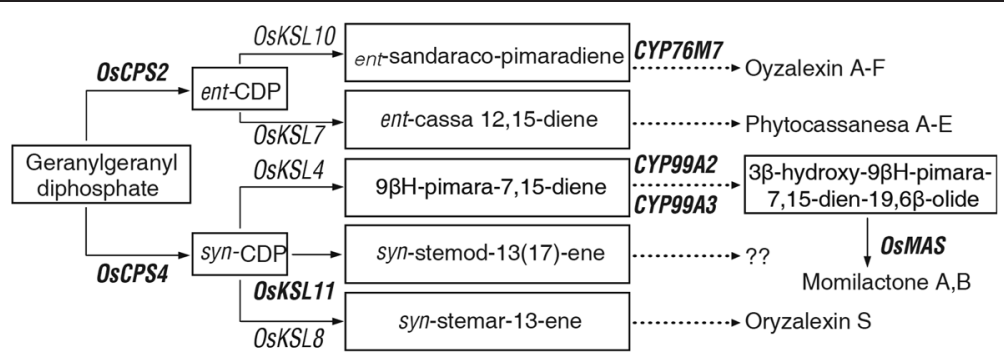

Fig. 5 The genes involved in phytoalexin biosynthesis were specifically induced in the resistant variety IR28 in response to $U$. virens infection. Known genes that are responsible for the biosynthesis of different types of phytoalexins were shown. Genes in bold were identified to be upregulated in $\mathrm{IR} 28$

genes were down-regulated simultaneously at $24 \mathrm{hpi}$ and 48 hpi. The conserved cis-elements in the promoter regions of the DEGs with similar expression patterns may provide clues as to how rice plants respond to pathogen infection. Eleven conserved motifs including five core elements of W-box and several DNA binding sites of Dof and Myb transcription factors were identified when comparing the promoter regions of up-regulated genes with those of down-regulated genes in IR28 (Additional file 13: Table S9). W-boxes, the binding sites of WRKY transcription factors, were significantly more abundant in the 5'regulatory regions of up-regulated DEGs in IR28. Strikingly, cis-element scanning in the PLACE database revealed that a cis-element CTAGCTAG, where the RY repeat motif has been found to be essential for seedspecific expression of some storage proteins, was identified to be significantly more enriched in the promoter regions of up-regulated $P R$ genes as compared to other $P R$ genes in IR28 (Table 2). The cis-element is even more abundant in the promoters of the up-regulated chitinase

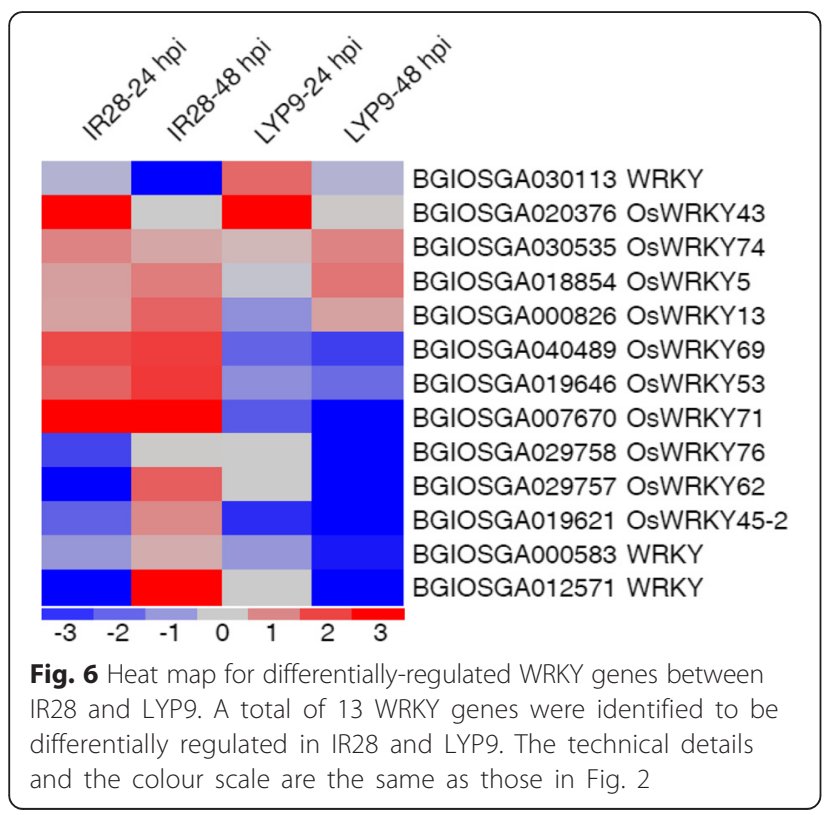

gene cluster. For comparison, the frequency of the ciselement in the 52 up-regulated kinase gene promoters is similar to that in other coding genes in the genome. These data suggest that the RY repeat is a cis-regulatory motif that is involved in the regulation of defense-related genes.

\section{Validation of DEGs by quantitative RT-PCR analyses}

To validate the DEGs identified by comparative transcriptome analyses, 14 DEGs that might be essential for RFS resistance were selected, and expression of these genes in response to pathogen inoculation was investigated by quantitative real-time RT-PCR (qRT-PCR). The qRT-PCR results showed that most of the tested genes were generally up-regulated at $24 \mathrm{hpi}$ and $48 \mathrm{hpi}$ in the resistant IR28 and down-regulated in the susceptible LYP9 (Fig. 7a and Additional file 14: Figure S5). The correlation between RNA-Seq and qRT-PCR data was further validated by comparing the corresponding expression data from both analyses. The $\log _{2}$ ratio values from transcriptome analyses were plotted against those from qRT-PCR. A clear correlation between two methods was found at $R^{2}=0.61$ (Fig. 7b). In general, qRT-PCR data confirm expression patterns of these important RFS resistance-related genes revealed by RNA-Seq analyses.

\section{Comparison of $U$. virens transcriptome in the resistant and susceptible cultivars during infection}

To compare expression profiles of $U$. virens during infection of the resistant and susceptible cultivars, clean RNA-Seq reads were mapped to the reference genome of $U$. virens [13] (Additional file 15: Table S10). Expression profiles of $U$. virens from the infected resistant cultivar IR28 were analyzed and compared with those from LYP9 described previously [13]. In IR28, 614 and 542 fungal genes were up-regulated significantly at 24 and 48 hpi compared with that from axenic cultures, respectively. Meanwhile, 425 and 247 genes were identified to be suppressed at 24 and $48 \mathrm{hpi}$, respectively. Interestingly, predicted host-pathogen interaction database (PHI-base) genes [46] that are probably involved in host- 
Table 2 RY repeat motifs enriched in the 5'-regulatory regions of $47 P R$ genes, particularly in 9 chitinase genes, which were up-regulated in IR28 and suppressed in LYP9

\begin{tabular}{|c|c|c|c|c|c|c|c|c|c|c|c|c|c|c|}
\hline \multirow[t]{2}{*}{ Motif_seq } & \multicolumn{3}{|c|}{ PR genes (47) } & \multicolumn{3}{|c|}{ Chitinase (9) } & \multicolumn{3}{|c|}{ PR genes (660) } & \multicolumn{3}{|c|}{ Protein kinases (52) } & \multirow[t]{2}{*}{ Annotation } & \multirow[t]{2}{*}{ Motif_ID } \\
\hline & $\overline{\text { Num }^{a}}$ & RAR $^{b}$ & $P_{\text {_value }}$ & Num & RAR & P_value & $\overline{\text { Num }}$ & RAR & $\overline{P \_ \text {value }}$ & Num & RAR & P_value & & \\
\hline ATGCATG & 31 & 6.3387 & $8.89 \mathrm{E}-13$ & 11 & 11.7459 & $3.85 \mathrm{E}-07$ & 174 & 2.5336 & $8.03 E-24$ & 6 & 1.1089 & 0.8205 & & S00010 \\
\hline CATGCAT & 55 & 5.1483 & 1.15E-15 & 16 & 7.8213 & 6.97E-07 & 337 & 2.2464 & $4.15 \mathrm{E}-31$ & 14 & 1.1845 & 0.5290 & RY repeat motif & S000105 \\
\hline ATGCAY & 69 & 4.4198 & $3.05 \mathrm{E}-15$ & 19 & 6.3557 & $2.10 \mathrm{E}-06$ & 462 & 2.1074 & 2.07E-33 & 20 & 1.1579 & 0.5860 & RY repeat motif & S00010 \\
\hline CATGCA & 92 & 3.5564 & $2.15 \mathrm{E}-13$ & 25 & 5.0468 & 7.38E-06 & 700 & 1.9270 & $6.24 \mathrm{E}-34$ & 28 & 0.9783 & 1.0000 & RY repeat motif & S000264 \\
\hline
\end{tabular}

${ }^{\mathrm{a}}$ The number of RY repeat motifs

${ }^{\mathrm{b}} \mathrm{RAR}=$ (motif count in a selected promoter set/number of promoters in the set)/(motif count in total promoters/number of total promoters)

$P$ values were calculated using Fisher's exact test

The total set of sequence-available $P R$ genes $(660)$ and that 52 protein kinase genes that were up-regulated in IR28 were used for comparisons

pathogen interactions were found to be significantly enriched in fungal DEGs from both rice genotypes, indicating their potential roles in pathogenicity of $U$. virens.

As shown in Venn diagrams (Additional file 16: Figure S6), gene expression profiles of $U$. virens in the resistant cultivar IR28 were much different from those in the susceptible LYP9, although 426 (266 up-regulated and 160 down-regulated) and 433 (285 up-regulated and 148 down-regulated) genes have similar expression patterns during infection of the resistant and susceptible cultivars at 24 and $48 \mathrm{hpi}$, respectively. GO enrichment analyses revealed that $U$. virens DEGs in two cultivars, especially for down-regulated genes, were enriched in different GO terms (Additional file 17: Table S11). Interestingly, GO terms in biological processes that are related to fungal multiplication and pathogenicity, such as reproductive process, sexual and asexual reproduction, sporulation and cell adhesion, were significantly enriched in down-regulated genes in the resistant IR28, but not in the susceptible LYP9. These results suggest that biological processes required for successful infection of $U$. virens are greatly suppressed in the resistant cultivar.

\section{Discussion}

RFS is a newly emerging fungal disease that causes severe yield loss and toxin contamination in rice grains [13]. Screening of rice genetic germplasm for RFS resistance revealed that certain cultivars exhibit relatively stable RFS resistance although no resistance gene has been reported so far. However, little is known about molecular mechanisms underlying durable resistance to RFS in rice. RNA-Seq is a recently developed approach that can be used in transcriptome analyses to reveal genome-wide expression profiling and regulation in plant hosts in response to pathogen infection. The technique has several advantages over other methods. First, RNA-Seq, unlike hybridization-based approaches, can detect gene transcripts despite not having the genome sequence of the target species. Second, RNA-Seq has low background noice [47]. Third, the technology has a higher sensitivity than DNA microarray and can be used to detect a larger dynamic range of expression levels of gene transcripts $[48,49]$.

In this study, RNA-Seq was used to identify genes differentially expressed between the cultivar IR28 with durable RFS resistance and susceptible cultivar LYP9 in response to $U$. virens at early infection stages. Comparative transcriptome analyses suggest that some important protein families including receptor-like kinases, WRKY transcription factors, PR proteins, and phytoalexin biosynthetic enzymes play important roles in RFS resistance. A clear correlation between RNA-Seq and qRT-PCR data confirmed expression patterns of the tested genes in response to $U$. virens infection (Fig. 7 and Additional file 16: Figure S6). Several transcriptome studies on the interaction of rice and $U$. virens have been reported recently $[37,38]$. Different from other transcriptome analyses, we analyzed and compared transcriptome profiles of the resistant and susceptible rice cultivars at the very early stage of infection (24 hpi and $48 \mathrm{hpi}$ ). Although gene expression profiles were partially different among those studies, a large proportion of DEGs revealed here were also reported in other transcriptome analyses. For instance, WRKY transcription factors, such as WRKY53 and WRKY69, were induced in different transcriptome studies. Additionally, some genes that had unique responses to $U$. virens infection revealed by Chao et al. [37], such as LOC_Os07g07870.1 and LOC_Os08g23790.1, had similar expression patterns in this study. Difference in expression patterns of partial DEGs might be due to different infection stages and different rice genotypes. It has been found that many rice genes had opposite regulation patterns between the early and late stages of $U$. virens infection [38].

\section{Pathogenesis-related proteins may be crucial for RFS resistance}

Cluster analyses showed that the majority of DEGs (inoculated vs. non-inoculated) in both genotypes were differentially regulated between the two cultivars in response to $U$. virens inoculation (Fig. 2). Among the group II genes, $47 P R$ genes were identified including members in the PR2-6, PR8 and PR9 families (Fig. 4). Some PR proteins, 


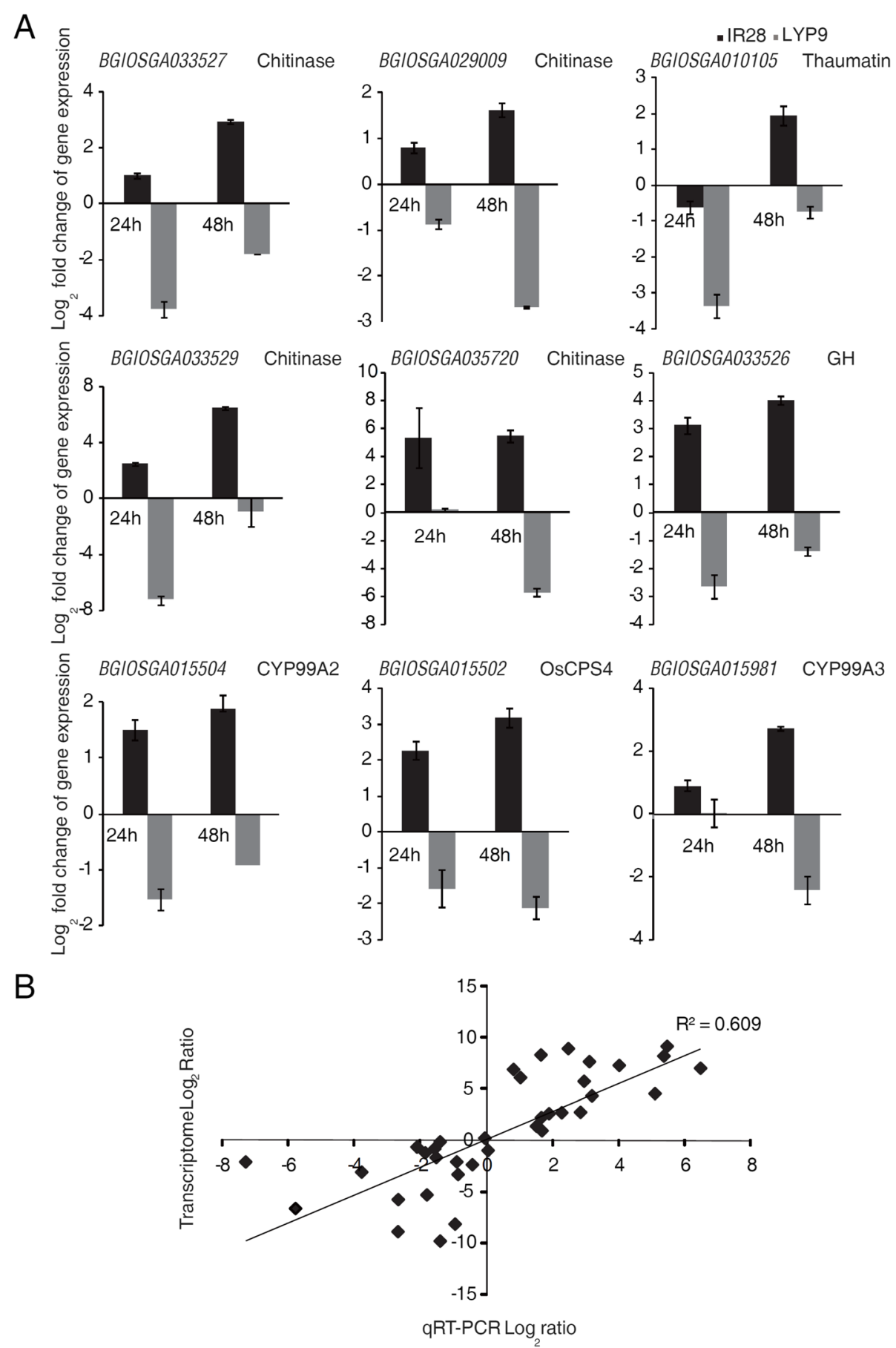

Fig. 7 Time-course expression analyses and validation of nine selected DEGs using quantitative real time RT-PCR. a Quantitative RT-PCR analyses of nine selected DEGs confirmed that these genes were up-regulated in IR28 and generally suppressed in LYP9 at both 24 and 48 hpi. Log fold change of transcript levels in the inoculated samples with respect to the transcript levels in mock-inoculated rice panicles was shown. Error bars represent standard errors for three replicates of qRT-PCR assays. $\mathbf{b}$ The linear correlation between RNA-Seq transcriptome profiles and qRT-PCR data. The $\log _{2}$ ratio values from transcriptome data were plotted against those of the qRT-PCR results. A correlation coefficient of 0.61 indicates that there is a good linear correlation between RNA-Seq and qRT-PCR data

such as $\beta$-1,3-glucanases, chitinases and proteinases have direct antifungal activities and hydrolyze molecules on the cell walls of fungal pathogens, including glucans, chitins and proteins directly $[50,51]$. Other PR proteins including thaumatin-like proteins and proteinase inhibitors have enzyme inhibitory activities and exert an effect against fungi 
by inactivating proteinases secreted by pathogens [52]. In addition, the peroxidase activity of PR-9 also contributes to fungal disease resistance by cross-linking and strengthening plant cell walls [53].

Consistent with our findings, $P R$ genes in rice have been shown to be induced by diverse biotic stresses including infection by the rice blast fungus $M$. oryzae [36], the bacterial blight pathogen Xanthomonas oryzae pv. oryzae [54], the sheath blight fungus Rhizoctonia solani $[55,56]$, and the rice dwarf virus (RDV) [57]. These expression data suggest that $P R$ genes have important roles in plant defenses against pathogen infection, which has been experimentally verified. Previous studies demonstrated that over-expression of the $P R$ genes encoding $\beta-1,3$-glucanases, chitinases and thaumatin-like proteins enhanced resistance to Fusarium head blight in wheat [58-61].

Preliminary mapping using 157 recombinant inbred lines derived from an inter-subspecies cross of Daguandao/IR28 identified a QTL conferring RFS resistance in the chromosome 11 in IR28 [62]. The QTL is physically close to the chitinase gene cluster region, out of which, nine chitinase genes were identified to be highly induced after $U$. virens inoculation (Fig. 4 and Additional file 9: Table S6). Another study showed that a QTL conferring resistance to $R$. solani was also mapped near to the chitinase gene cluster region [63], suggesting that the chitinase gene cluster might be involved in broad-spectrum and durable disease resistance. Notably, clean RNA-Seq reads of the susceptible cultivar LYP9 were mapped to these chitinase genes and it was found that no gene in the chitinase cluster was absent from the genome of LYP9. Collectively, these differentially regulated $P R$ genes in the resistant and susceptible genotypes might play essential roles in rice resistance against $U$. virens.

\section{Diterpene phytoalexins are important for RFS resistance}

Diterpene phytoalexins, secondary metabolites with a low molecular mass, have anti-microbial activity and play important roles in plant defense responses $[64,65]$. In this study, seven diterpene phytoalexin biosynthesis genes were identified to be significantly up-regulated in the resistant variety and weakly or not induced in the susceptible variety after inoculation (Fig. 5 and Additional file 10: Table S7). Among them, OsCPS4, CYP99A2, CYP99A3 and OsMAS are responsible for different steps in the biosynthesis of momilactone A and B (Fig. 5). Knock-down of OsCPS4 caused lower accumulation levels of momilactones and oryzalexin $\mathrm{S}$ and the cps 4 rice mutant is more susceptible to $M$. oryzae infection than the wild-type [66]. Simultaneous knock-down of CYP99A2 and CYP99A3 specifically suppressed elicitor-inducible production of momilactones [67]. Additionally, OsCPS2 and CYP76M7 are physically located on the same gene cluster involved in biosynthesis of the antifungal phytocassanes [68]. OsCPS2 expression in the resistant rice cultivar IL7 was upregulated at $2 \mathrm{~d}$ after $M$. oryzae inoculation, resulting in enhanced phytoalexin production [40]. OsKSL11 is another gene where expression was elevated in IR28 after $U$. virens infection. OsKSL11 has been found to react with syn-CDP and produce syn-stemod-13(17)-ene [69]. These results suggest that production of phytoalexins, in particular momilactones, is highly induced by $U$. virens infection in rice and can play a key role in RFS resistance.

\section{Conserved cis-elements are involved in the regulation of defense responses against $U$. virens infection}

A recent study reported that the $U$. virens regulated genes shared highly conserved cis-elements in the promoters including W-boxes, the DNA binding sites of Myb and Dof proteins, which is highly consistent with our cis-element enrichment analyses (Additional file 13: Table S9) [37]. WRKY transcription factors are vital components in plant defense against pathogens [70]. WRKY proteins can regulate phytoalexin production and $P R$ gene expression through binding to the cis-regulatory element W-box. This study revealed that 13 WRKY transcription factors were differentially regulated in both the resistant and susceptible cultivars after $U$. virens infection. In particular, OsWRKY53, OsWRKY69 and OsWRKY71 were found to be highly up-regulated in IR28 and suppressed in LYP9 (Additional file 11: Table S8). It was demonstrated that transgenic rice plants over-expressing OsWRKY53 and OsWRKY71 exhibited enhanced resistance to blast disease and X. oryzae pv. oryzae infection [71-73]. Both Dof and Myb proteins are also important transcription factors that are involved in the regulation of plant defenses and biotic stress resistance [74, 75]. Taken together, these findings imply that some WRKY, Dof and Myb transcription factors, such as OsWRKY53, OsWRKY69 and OsWRKY71, play important roles in rice transcriptome regulation during $U$. virens infection.

Furthermore, the cis-regulatory RY repeat motif was found to be significantly more abundant in the promoter regions of these differentially regulated $P R$ genes than other $P R$ genes, even though the motif is generally enriched in the $P R$ gene promoters. These results suggest that the seed-specific cis-element may be also involved in the expression regulation of defense-related genes in response to $U$. virens infection.

Defense-oriented reprogramming of protein kinase genes in rice during early infection of $U$. virens

Many protein kinase genes were reported to be transcriptionally regulated in host plants upon pathogen infection [76]. In agreement with this, we found here that 52 protein kinase genes were highly induced in IR28 after $U$. virens infection. Among these, three categories 
of receptor-like kinases including lectin-, LRR- and LysM-containing transmembrane kinases were identified which are often involved in the recognition of pathogens by sensing pathogen-associated molecular patterns [77]. Many LysM receptor-like kinases can mediate plant defense responses against fungal pathogens likely through chitin perception [78, 79]. BGIOSGA016815, a lectin receptor kinase, was also identified to be induced in response to bacterial, parasite, fungal and viral infection in rice [80]. Other up-regulated kinase genes encode cytoplasmic kinases that function in the phospho-relay and are essential components in defense signaling. For instance, OsMAPKK4 is phosphorylated by upstream MAPKKK7 (BGIOSGA000957) that was induced by $U$. virens infection in IR28, which prompts signal transduction in response to various biotic and abiotic stresses including pathogen, insect, drought, salinity, flood and cold [81]. Therefore, we speculate that these differential regulated protein kinases may play crucial roles in RFS resistance signaling.

\section{Conclusion}

In the present study, comparison of expression profiles between the resistant cultivar IR28 and the susceptible LYP9 during early stages of $U$. virens infection uncovered a clear difference in the regulation of defense responses against $U$. virens between the two genotypes. A genome-wide view of expression profiles of the resistant rice cultivar in response to $U$. virens infection promotes understanding of molecular mechanisms underlying RFS resistance. A specific set of protein kinases, PR proteins, WRKY transcription factors, and secondary metabolites including phytoalexins were found to be crucial for RFS resistance. Transgenic rice plants over-expressing some of the identified genes are being developed to confirm their biological functions in RFS resistance. The information revealed by transcriptome analyses will also facilitate the isolation of QTLs associated with resistance to $U$. virens in rice.

\section{Methods}

\section{Rice materials and fungal inoculation}

Oryza sativa L. spp. indica cultivars IR28 (resistant to RFS) and LYP9 (highly susceptible but high-yielding) were grown at the experiment station of Jiangsu Academy of Agricultural Sciences in Nanjing, Jiangsu, China. $U$. virens $37-1$ and 39-3 were monospore isolates from samples collected at paddy fields in Jiangsu Province, China, and the P1 isolate originating from Kansas, USA was courtesy of Professor Jinrong Xu, Purdue University. Rice panicles were inoculated with a mixture of conidial and hyphal fragments as described with minor modifications [82]. Briefly, the $U$. virens isolates were cultured in potato sucrose broth (PSB, fresh potato extract and $2 \%$ sucrose) on an incubator shaker at $120 \mathrm{rpm}$ and $28{ }^{\circ} \mathrm{C}$ for a week. The panicles of rice plants at the booting stage were inoculated with conidial suspensions $\left(2 \times 10^{5}\right.$ conidia $\left.\mathrm{ml}^{-1}\right)$ at 5 to 7 days before earing. Rice panicles injected with PSB were used as mock controls. The pathogen- or mock-inoculated panicles were harvested at 24 and $48 \mathrm{hpi}$, immediately frozen in liquid nitrogen, and then kept at $-70{ }^{\circ} \mathrm{C}$ for RNA isolation. Some inoculated rice plants were grown further for disease symptom observations three weeks after inoculation.

\section{Preparation of cDNA libraries for RNA-Seq}

Total RNA was isolated using RNApure ${ }^{\circ}$ total RNA rapid extraction kit according to the manufacturer's instruction (Aidlab Biotechnologies, Beijing). The yield and purity of RNA were evaluated by measurement of absorbance at 260 and $280 \mathrm{~nm}$. RNA integrity was confirmed using Agilent 2100 Bioanalyzer (Agilent Technologies) with a minimum RNA integrated number (RIN) value of 7.0. Total RNA isolated from the samples of three biological replicates at each time point (24 and $48 \mathrm{hpi}$ ) was combined for RNA-Seq. Poly (A) + mRNA was enriched from total RNA using oligo(dT) magnetic beads and used for library construction. RNA-Seq libraries were constructed following the standard pipeline at Beijing Genomics Institute (BGI) in Shenzhen, China. Reads of 49 bp length were generated with the Illumina HiSeq $^{\text {mim }} 2000$ sequencing platform at BGI.

\section{Mapping reads to the reference genome and annotated genes}

Raw reads were downloaded from BGI in FASTQ format. The reference genome of Oryza sativa L. ssp. indica 93-11 and associated gene information were downloaded from Gramene (http://www.gramene.org/) and the Rice Genome Annotation Project (http://rice.plantbiology.msu.edu). The genome of $U$. virens isolate UV-8b was used as the reference for analyzing $U$. virens transcriptome [13]. Prior to mapping reads to the reference databases, all reads were filtered to remove adaptor sequences, and eliminate reads in which the percentage of unknown bases $(\mathrm{N})$ was greater than $10 \%$, or the percentage of the low quality bases (bases with Phred quality score $\leq 5$ ) in a read exceeded $50 \%$. The resultant clean reads were mapped to rice and $U$. virens genomes using SOAP2 [83]. No more than two mismatches were allowed in the alignment for each read.

\section{Analysis and screening of differentially expressed genes}

RPKM (Reads per kb per Million reads) was used to represent the gene expression level of rice and $U$. virens transcripts [48]. Differentially expressed genes (DEGs) in rice cultivars were identified through comparing gene expression levels between $U$. virens- and mock-inoculated panicles with the criteria of the absolute $\log _{2}$ ratio value $\geq 1$ 
and false discovery rate $(\mathrm{FDR}) \leq 0.001$ [84]. DEGs of $U$. virens were identified by comparing the gene expression level during infection with that in axenic cultures using the same criteria. The DEGs of rice and $U$. virens were then subjected to GO enrichment analyses using the WEGO (Web Gene Ontology Annotation Plotting) program, respectively [85]. P-values were calculated by comparing the observed frequency of an annotation term with the frequency expected in respective genome using Pearson's chi-squared test. The Kyoto Encyclopedia of Genes and Genomes (KEGG) pathway enrichment analysis was performed to identify significantly enriched metabolic pathways or signal transduction pathways in rice DEGs comparing with the whole genome background. Pathways with Q-values $\leq 0.05$ are considered significantly enriched in DEGs as assessed with the PAICE program [86]. Hierarchical clustering of all DEGs was performed using cluster 3.0 [87].

\section{Conserved cis-elements searches}

The $1.5 \mathrm{~kb}$ sequences upstream of the start codon of selected genes in rice were scanned for putative conserved cis-elements identical with or similar to the motifs in PLACE database [88]. The enriched motifs in the upregulated genes were determined by comparing frequency in the up-regulated genes with that in down-regulated genes (chi-square test, $P<0.01$ ). Alternatively, Relative Appearance Ratio (RAR) of motifs was calculated using the formula (motif counts in a selected promoter set/ number of promoters in the set)/(motif counts in total promoters/number of total promoters) [89]. $P$ values comparing motif frequency in selected gene sets with that in total genes were calculated using Fisher's exact test. The conserved motifs were identified with the criteria of RAR $\geq 3$ and $P$ value $<0.01$.

\section{Validation of RNA-Seq data by quantitative real-time RT-PCR}

Some differentially regulated genes identified through RNA-Seq were validated by qRT-PCR. The primer sets used for qRT-PCR were designed based on exon sequences of the selected genes using the online program, oligo analyzer (http://www.idtdna.com) and the specificity of PCR primers was evaluated by blasting primer sequences against the NCBI database (Additional file 18: Table S12). Total RNA $(2 \mu \mathrm{g})$ was used for cDNA synthesis with MLV reverse transcriptase (Invitrogen). PCR was performed in $20 \mu \mathrm{l}$ of reaction mix containing $0.4 \mu \mathrm{l}$ cDNA, $10 \mu \mathrm{l}$ SYBR Premix Ex Taq ${ }^{\text {ma }}$ (Takara, Dalian), $0.4 \mu$ ROX reference dye, and $0.4 \mu \mathrm{l}$ of each primer $(10 \mu \mathrm{M})$ using an ABI Prism 7000 System (Applied Biosystems, Foster City, CA). Three replicates for each biological replicate were performed with similar results. Relative gene expression was calculated using the $2^{-\triangle \mathrm{C} t}$ method [90].

\section{Additional files}

Additional file 1: Figure S1. Disease symptoms observed on LYP9 and IR28 panicles three weeks after $U$. virens P1 inoculation. False smut balls formed on a representative LYP9 panicle $(\mathbf{A})$ and on a representative IR28 panicle (B) after P1 inoculation. The number of false smut balls formed on LYP9 panicles was significantly more than that on IR28 panicles. (TIFF $21 \mathrm{~kb}$ )

Additional file 2: Table S1. Statistics of the total RNA-Seq reads and reads mapped to the Oryza sativa $L$. ssp. indica reference genome at different inoculation time points in IR28 and LYP9. (XLSX 21 kb)

Additional file 3: Figure S2. Saturation analyses of RNA-Seq data. The number of detected genes approached saturation when RNA sequencing reads reached $\sim 3$ million for each library. (TIFF $21 \mathrm{~kb}$ )

Additional file 4: Table S2. The differentially expressed genes that exhibited opposite expression patterns between IR28 and LYP9 at 24 hpi and 48 hpi. (XLSX $21 \mathrm{~kb}$ )

Additional file 5: Table S3. The enriched $\mathrm{GO}$ terms for the genes that were up-regulated in IR28 and LYP9 at 24 hpi and 48 hpi. (XLSX 21 kb)

Additional file 6: Figure S3. The expression pattern of DEGs in the enriched GO term "transferase activity" (GO: 0016740) specific to IR28. A total of 142 transferase genes were identified to be differentially regulated in IR28 in response to $U$. virens infection at 24 and $48 \mathrm{hpi}$. Black dots indicate the transferase genes encoding protein kinases. Each column represents the $\mathrm{Log}_{2}$ fold change in gene transcript levels in rice at the indicated times, relative to the levels of mock-inoculated samples. The vertical dimension represents the transferase genes that exhibited changes in transcript level (cutoff: $\mid \log _{2}[$ fold change] $\mid \geq 1$ and FDR $\leq 0.001$ ). The colour scale indicates transcript abundance relative to the mockinoculated panicles: red, increase in relative transcript abundance; blue, decrease in relative transcript abundance. (TIFF $21 \mathrm{~kb}$ )

Additional file 7: Table S4. Protein kinase genes in the GO term "transferase activity" (GO: 0016740) that were induced by U. virens in IR28 and repressed in LYP9. (XLSX $21 \mathrm{~kb}$ )

Additional file 8: Table S5. The enriched signaling and biosynthetic pathways of DEGs in IR28 and LYP9 at 24 hpi and 48 hpi revealed by KEGG enrichment analysis. (XLSX $21 \mathrm{~kb}$ )

Additional file 9: Table S6. Differentially expressed $P R$ genes between IR28 and LYP9 at $24 \mathrm{~h}$ and $48 \mathrm{~h}$ after U. virens infection. (XLSX $21 \mathrm{~kb}$ )

Additional file 10: Table S7. Differential expression of phytoalexin synthesis genes in the susceptible variety LYP9 and the resistant variety IR28 at the early infection stages of U. virens (24 hpi and 48 hpi). (XLSX $21 \mathrm{~kb}$ )

Additional file 11: Table S8. Differentially expressed WRKY genes in IR28 and LYP9 at $24 \mathrm{~h}$ and $48 \mathrm{~h}$ after U. virens infection. (XLSX $22 \mathrm{~kb}$ )

Additional file 12: Figure S4. Venn diagrams showing the number of genes that exhibited similar expression patterns between 24 hpi and 48 hpi in IR28 (R) and in LYP9 (S). (TIFF $21 \mathrm{~kb}$ )

Additional file 13: Table S9. The conserved motifs that were more abundant in the 5'-regulatory regions of up-regulated genes compared with down-regulated genes in IR28. (XLSX $21 \mathrm{~kb}$ )

Additional file 14: Figure S5. Quantitative real-time RT-PCR analyses of six more differentially regulated genes in rice. The results showed that these genes were generally up-regulated in IR28 and suppressed in LYP9 at both 24 and $48 \mathrm{hpi}$, which is well consistent with transcriptome data. $\log _{2}$ fold change of transcript levels in the inoculated samples with respect to the transcript levels in mock-inoculated rice panicles was shown. Error bars represent standard errors for three replicates of qRT-PCR assays. (TIFF $21 \mathrm{~kb}$ )

Additional file 15: Table S10. Statistics of RNA-Seq reads mapped to the reference genome of $U$. virens at $24 \mathrm{~h}$ and $48 \mathrm{~h}$ after inoculation in IR28 and LYP9. (XLSX $21 \mathrm{~kb}$ )

Additional file 16: Figure S6. Venn diagrams of differentially regulated U. virens genes in IR28 (R) and in LYP9 (S) at 24 hpi and 48 hpi. The majority of up-regulated (A) and down-regulated genes (B) exhibited different expression patterns in IR28 (R) and LYP9 (S) although a large proportion of DEGs shared the similar regulation patterns. (TIFF $21 \mathrm{~kb}$ ) 
Additional file 17: Table S11. The enriched GO terms under three different categories for up-regulated and down-regulated $U$. virens genes in IR28 and LYP9. (XLSX $21 \mathrm{~kb}$ )

Additional file 18: Table S12. The primers designed for quantitative real-time RT-PCR. For each gene, the forward (F) and reverse (R) primer sequences were listed. (XLSX $21 \mathrm{~kb})$

\section{Competing interests}

The authors declare that they have no competing interests.

\section{Authors' contributions}

$\mathrm{YH}$ and $\mathrm{KZ}$ contributed equally to this research. WS and $\mathrm{YH}$ conceived and designed the experiments. $Y H, K Z, J Y, N Z, A F$ and $Y Z$ conducted the experiments and analyzed data. $\mathrm{YL}, \mathrm{ZC}$ and $\mathrm{TH}$ contributed reagents and materials. YH, TH and WS wrote the manuscript. All authors have read and approved the final manuscript.

\section{Acknowledgements}

We thank Jinrong $\mathrm{Xu}$ at Purdue University for providing the U. virens isolate P1. The work is supported by the transgenic crop project 2012ZX08009003-003, National Natural Science Foundation of China grant 31471728, the National High Technology Research and Development program of China 2012AA100703, and the 111 project B13006 to W. S.

\section{Author details}

'Department of Plant Pathology, China Agricultural University, 2 West Yuanmingyuan Rd., Haidian District, Beijing 100193, China. ${ }^{2}$ Key Laboratory of Plant Pathology, Ministry of Agriculture, China Agricultural University, Beijing 100193, China. Institute of Plant Protection, Jiangsu Academy of Agricultural Sciences, Nanjing 210014, China. ${ }^{4}$ School of Environmental Sciences, University of Guelph, Guelph, ON N1G 2 W1, Canada.

\section{Received: 5 September 2014 Accepted: 3 November 2015}

Published online: 16 November 2015

\section{References}

1. Ladhalakshmi D, Laha GS, Singh R, Karthikeyan A, Mangrauthia SK, Sundaram RM, et al. Isolation and characterization of Ustilaginoidea virens and survey of false smut disease of rice in India. Phytoparasitica. 2012;40(2):171-6.

2. Cooke MC. Some extra-European fungi. Grevillea. 1878;7:13-5.

3. Guo X, Li Y, Fan J, Li L, Huang F, Wang W. Progress in the study of false smut disease in rice. J Agr Sci Tech. 2012;A2:1211-7.

4. Rush MC, Shahjahan A, Jones JP, Groth DE. Outbreak of false smut of rice in Louisiana. Plant Dis. 2000;84(1):100.

5. Sanghera GS, Ahanger MA, Kashyap SC, Bhat ZA, Rather AG, Parray GA. False smut of rice (Ustilaginoidea virens) under temperate agro-climatic conditions of Kashmir, India. Elixir Bio Tech. 2012;49:9827-31.

6. Koiso Y, Li Y, Iwasaki S, Hanaoka K, Kobayashi T, Sonoda R, et al. Ustiloxins, antimitotic cyclic peptides from false smut balls on rice panicles caused by Ustilaginoidea virens. J Antibiot. 1994;47(7):765-73.

7. Zhou YL, Pan YJ, Xie XW, Zhu LH, Xu JL, Wang S, et al. Genetic diversity of rice false smut fungus, Ustilaginoidea virens and its pronounced differentiation of populations in North China. J Phytopathol. 2008;156(9):559-64.

8. Ludueña RF, Roach MC, Prasad V, Banerjee M, Koiso Y, Li Y, et al. Interaction of ustiloxin A with bovine brain tubulin. Biochem Pharmacol. 1994:47(9):1593-9.

9. Miyazaki S, Matsumoto Y, Uchihara T, Morimoto K. High-performance liquid chromatographic determination of ustiloxin $\mathrm{A}$ in forage rice silage. J Vet Med Sci. 2009;71(2):239-41.

10. Kim KW, Park EW. Ultrastructure of spined conidia and hyphae of the rice false smut fungus Ustilaginoidea virens. Micron. 2007;38(6):626-31.

11. Zhou YL, Izumitsu K, Sonoda R, Nakazaki T, Tanaka E, Tsuda M, et al. PCR-based specific detection of Ustilaginoidea virens and Ephelis japonica. J Phytopathol. 2003;151(9):513-8.

12. Ashizawa T, Takahashi M, Moriwaki J, Hirayae K. Quantification of the rice false smut pathogen Ustilaginoidea virens from soil in Japan using real-time PCR. Eur J Plant Pathol. 2010;128(2):221-32.

13. Zhang Y, Zhang K, Fang A, Han Y, Yang J, Xue M, et al. Specific adaptation of Ustilaginoidea virens in occupying host florets revealed by comparative and functional genomics. Nat Commun. 2014;5:3849.
14. Wang LP, Dong MZ, Hao ZN, Tao RX. Preliminary study on resistance of rice varieties to rice false smut by using method of natural infection in Zhejiang province. Acta Agric Jiangxi. 2010;22(7):73-4

15. Cartwright RD, Lee FN, Beaty T, Sutton EA, Parsons CE. Reaction of rice cultivars/lines to false smut, stem rot, and black sheath rot disease. Univ Arkansas Agric Exp Stn Res Ser. 2000;476:158-68.

16. Biswas A. False smut disease of rice: a review. Environ Ecol. 2001;19(1):67-83.

17. Li Y, Zhu Z, Zhang Y, Zhao L, Wang C. Genetic analysis of rice false smut resistance using mixed major genes and polygenes inheritance model. Acta Agron Sin. 2008;34(10):1728-33.

18. Xu J, Xue Q, Luo L, Li Z. Preliminary report on quantitative trait loci mapping of false smut resistance using near-isogenic introgression lines in rice. Acta Agric Zhejiang. 2001;14(1):14-9.

19. Zhou YL, Xie XW, Zhang F, Wang S, Liu XZ, Zhu LH, et al. Detection of quantitative resistance loci associated with resistance to rice false smut (Ustilaginoidea virens) using introgression lines. Plant Pathol. 2014;63(2):365-72

20. Jones JD, Dangl JL. The plant immune system. Nature. 2006:444(7117):323-9.

21. Muthamilarasan M, Prasad M. Plant innate immunity: An updated insight into defense mechanism. J Biosci. 2013:38(2):1-17.

22. $F u Z Q$, Dong $X$. Systemic acquired resistance: turning local infection into global defense. Annu Rev Plant Biol. 2013;64:839-63.

23. van Loon LC, Rep M, Pieterse C. Significance of inducible defense-related proteins in infected plants. Annu Rev Phytopathol. 2006:44:135-62.

24. Uknes S, Mauch-Mani B, Moyer M, Potter S, Williams S, Dincher S, et al. Acquired resistance in Arabidopsis. Plant Cell. 1992;4(6):645-56.

25. Leubner-Metzger G, Meins F. Functions and regulation of plant $\beta-1,3-$ glucanases (PR-2). In: Datta SK, Muthukrishnan S, editors. Pathogenesisrelated proteins in plants. Boca Raton, Fla: CRC Press; 1999. p. 49-76.

26. Kasprzewska A. Plant chitinases-regulation and function. Cell Mol Biol Letters. 2003;8(3):809-24

27. Almagro L, Ros LG, Belchi-Navarro S, Bru R, Barceló AR, Pedreño MA. Class III peroxidases in plant defence reactions. J Exp Bot. 2009:60(2):377-90.

28. Hiraga S, Sasaki K, Ito H, Ohashi Y, Matsui H. A large family of class III plant peroxidases. Plant Cell Physiol. 2001:42(5):462-8.

29. Bagnaresi $P$, Biselli $C$, Orrù L, Urso S, Crispino L, Abbruscato $P$, et al. Comparative transcriptome profiling of the early response to Magnaporthe oryzae in durable resistant vs susceptible rice (Oryza sativa L.) genotypes. PLOS ONE. 2012;7(12):e51609.

30. Zheng W, Ma L, Zhao J, Li Z, Sun F, Lu X. Comparative transcriptome analysis of two rice varieties in response to rice stripe virus and small brown planthoppers during early interaction. PLoS ONE. 2013;8(12), e82126.

31. Xiao J, Jin X, Jia X, Wang H, Cao A, Zhao W, et al. Transcriptome-based discovery of pathways and genes related to resistance against Fusarium head blight in wheat landrace Wangshuibai. BMC Genomics. 2013:14:197.

32. Zhang S, Xiao Y, Zhao J, Wang F, Zheng Y. Digital gene expression analysis of early root infection resistance to Sporisorium reilianum $f$. sp. zeae in maize. Mol Genet Genomics. 2013:288(1-2):21-37.

33. $X u$ L, Zhu L, Tu L, Liu L, Yuan D, Jin L, et al. Lignin metabolism has a central role in the resistance of cotton to the wilt fungus Verticillium dahliae as revealed by RNA-Seq-dependent transcriptional analysis and histochemistry. J Exp Bot. 2011;62(15):5607-21.

34. Kim KH, Kang YJ, Kim DH, Yoon MY, Moon J, Kim MY, et al. RNA-Seq analysis of a soybean near-isogenic line carrying bacterial leaf pustule-resistant andsusceptible alleles. DNA Res. 2011;18(6):483-97.

35. Li C, Deng G, Yang J, Viljoen A, Jin Y, Kuang $R$, et al. Transcriptome profiling of resistant and susceptible Cavendish banana roots following inoculation with Fusarium oxysporum f. sp. cubense tropical race 4. BMC Genomics. 2012;13:374

36. Kawahara Y, Oono Y, Kanamori H, Matsumoto T, Itoh T, Minami E. Simultaneous RNA-Seq analysis of a mixed transcriptome of rice and blast fungus interaction. PLOS ONE. 2012;7(11), e49423.

37. Chao J, Jin J, Wang D, Han R, Zhu R, Zhu Y, et al. Cytological and transcriptional dynamics analysis of host plant revealed stage-specific biological processes related to compatible rice-Ustilaginoidea virens interaction. PLoS ONE. 2014;9(3), e91391.

38. Fan J, Guo XY, Li L, Huang F, Sun WX, Huang YY, et al. Infection of Ustilaginoidea virens intercepts rice seed formation but activates grain-fillingrelated genes. J Integr Plant Biol. 2015;57(6):577-590.

39. Hu M, Luo L, Wang S, Liu Y, Li J. Infection processes of Ustilaginoidea virens during artificial inoculation of rice panicles. Eur J Plant Pathol. 2014:139(1):67-77. 
40. Dixon RA. Natural products and plant disease resistance. Nature. 2001; 411(6839):843-7.

41. Hasegawa M, Mitsuhara I, Seo S, Imai T, Koga J, Okada K, et al. Phytoalexin accumulation in the interaction between rice and the blast fungus. Mol Plant-Microbe Interact. 2010;23(8):1000-11

42. Grayer RJ, Kokubun T. Plant - fungal interactions: the search for phytoalexins and other antifungal compounds from higher plants. Phytochemistry. 2001; 56(3):253-63.

43. Okada K. The biosynthesis of isoprenoids and the mechanisms regulating it in plants. Biosc Biotech Bioch. 2011;75(7):1219-25.

44. Pandey SP, Somssich IE. The role of WRKY transcription factors in plant immunity. Plant Physiol. 2009;150(4):1648-55.

45. Rushton PJ, Somssich IE, Ringler P, Shen QJ. WRKY transcription factors. Trends Plant Sci. 2010;15(5):247-58.

46. Winnenburg R, Baldwin TK, Urban M, Rawlings C, Kohler J, Hammond-Kosack KE. PHI-base: a new database for pathogen host interactions. Nucleic Acids Res. 2006:34:D459-64.

47. Wang Z, Gerstein M, Snyder M. RNA-Seq: a revolutionary tool for transcriptomics. Nat Rev Genet. 2009;10(1):57-63.

48. Nagalakshmi U, Wang Z, Waern K, Shou C, Raha D, Gerstein M, et al. The transcriptional landscape of the yeast genome defined by RNA sequencing. Science. 2008;320(5881):1344-9.

49. Mortazavi A, Williams BA, McCue K, Schaeffer L, Wold B. Mapping and quantifying mammalian transcriptomes by RNA-Seq. Nat Methods. 2008;5(7): 621-628.50.

50. van Loon LC, Van Strien EA. The families of pathogenesis-related proteins, their activities, and comparative analysis of PR-1 type proteins. Physiol Mol Plant Pathol. 1999:55(2):85-97.

51. Edreva A. Pathogenesis-related proteins: research progress in the last 15 years Gen Appl Plant Physiol. 2005;31(1-2):105-24.

52. Hejgaard J, Jacobsen S, Svendsen IB. Two antifungal thaumatin-like proteins from barley grain. FEBS Lett. 1991;291(1):127-31.

53. Passardi F, Penel C, Dunand C. Performing the paradoxical: how plant peroxidases modify the cell wall. Trends Plant Sci. 2004;9(11):534-40.

54. Yin Z, Chen J, Zeng L, Goh M, Leung H, Khush GS, et al. Characterizing rice lesion mimic mutants and identifying a mutant with broad-spectrum resistance to rice blast and bacterial blight. Mol Plant-Microbe Interact. 2000;13(8):869-76.

55. Lee J, Bricker TM, Lefevre M, Pinson SR, Oard JH. Proteomic and genetic approaches to identifying defence-related proteins in rice challenged with the fungal pathogen Rhizoctonia solani. Mol Plant Pathol. 2006;7(5):405-16.

56. Zhao C, Wang A, Shi Y, Wang L, Liu W, Wang Z, et al. Identification of defense-related genes in rice responding to challenge by Rhizoctonia solani. Theor Appl Genet. 2008;116(4):501-16.

57. Shimizu T, Satoh K, Kikuchi S, Omura T. The repression of cell wall-and plastidrelated genes and the induction of defense-related genes in rice plants infected with rice dwarf virus. Mol Plant-Microbe Interact. 2007;20(3):247-54.

58. Li WL, Faris JD, Muthukrishnan S, Liu DJ, Chen PD, Gill BS. Isolation and characterization of novel CDNA clones of acidic chitinases and $\beta-1,3-$ glucanases from wheat spikes infected by Fusarium graminearum. Theor Appl Genet. 2001;102(2-3):353-62.

59. Anand A, Zhou T, Trick HN, Gill BS, Bockus WW, Muthukrishnan S. Greenhouse and field testing of transgenic wheat plants stably expressing genes for thaumatin-like protein, chitinase and glucanase against Fusarium graminearum. J Exp Bot. 2003;54(384):1101-11.

60. Chen WP, Chen PD, Liu DJ, Kynast R, Friebe B, Velazhahan R, et al. Development of wheat scab symptoms is delayed in transgenic wheat plants that constitutively express a rice thaumatin-like protein gene. Theor Appl Genet. 1999:99(5):755-60.

61. Pritsch C, Muehlbauer GJ, Bushnell WR, Somers DA, Vance CP. Fungal development and induction of defense response genes during early infection of wheat spikes by Fusarium graminearum. Mol Plant-Microbe Interact. 2000;13(2):159-69.

62. Li YS, Huang SD, Yang J, Wang CL. Analysis of quantitative trait loci for resistance to rice false smut. Acta Agron Sin. 2011;37:778-83.

63. Channamallikarjuna V, Sonah H, Prasad M, Rao G, Chand S, Upreti HC, et al. Identification of major quantitative trait loci qSBR11-1 for sheath blight resistance in rice. Mol Breeding. 2010;25(1):155-66.

64. Hammerschmidt R. Phytoalexins: what have we learned after 60 years? Annu Rev Phytopathol. 1999;37:285-306.

65. Pedras MSC, Yaya EE, Glawischnig E. The phytoalexins from cultivated and wild crucifers: chemistry and biology. Nat Prod Rep. 2011;28(8):1381-405.
66. Toyomasu T, Usui M, Sugawara C, Otomo K, Hirose Y, Miyao A, et al. Reverse-genetic approach to verify physiological roles of rice phytoalexins: characterization of a knockdown mutant of OsCPS4 phytoalexin biosynthetic gene in rice. Physiol Plant. 2014;150(1):55-62

67. Shimura K, Okada A, Okada K, Jikumaru Y, Ko K, Toyomasu T, et al. Identification of a biosynthetic gene cluster in rice for momilactones. J Biol Chem. 2007; 282(47):34013-8.

68. Swaminathan S, Morrone D, Wang Q, Fulton DB, Peters RJ. CYP76M7 is an ent-cassadiene C11 a-hydroxylase defining a second multifunctional diterpenoid biosynthetic gene cluster in rice. Plant Cell. 2009;21(10):3315-25.

69. Morrone D, Jin Y, Xu M, Choi S, Coates RM, Peters RJ. An unexpected diterpene cyclase from rice: functional identification of a stemodene synthase. Arch Biochem Biophys. 2006;448(1-2):133-40.

70. Ross CA, Liu Y, Shen QJ. The WRKY gene family in rice (Oryza sativa). J Integr Plant Biol. 2007:49(6):827-42.

71. Liu X, Bai $X$, Wang $X$, Chu C. OsWRKY71, a rice transcription factor, is involved in rice defense response. J Plant Physiol. 2007;164(8):969-79.

72. Qiu D, Xiao J, Ding X, Xiong M, Cai M, Cao Y, et al. OsWRKY13 mediates rice disease resistance by regulating defense-related genes in salicylate-and jasmonate-dependent signaling. Mol Plant-Microbe Interact. 2007:20(5):492-9.

73. Chujo T, Takai R, Akimoto-Tomiyama C, Ando S, Minami E, Nagamura Y, et al. Involvement of the elicitor-induced gene OsWRKY53 in the expression of defense-related genes in rice. BBA-Gene Struct Expr. 2007;1769(7):497-505.

74. Yanagisawa S. Dof domain proteins: plant-specific transcription factors associated with diverse phenomena unique to plants. Plant Cell Physiol. 2004:45(4):386-91.

75. Ambawat S, Sharma P, Yadav NR, Yadav RC. MYB transcription factor genes as regulators for plant responses: an overview. Physiol Mol Biol Plants. 2013; 19(3):307-21.

76. Yazawa T, Kawahigashi H, Matsumoto T, Mizuno H. Simultaneous transcriptome analysis of Sorghum and Bipolaris sorghicola by using RNA-Seq in combination with de novo transcriptome assembly. PLOS ONE. 2013;8(4), e62460.

77. Wu Y, Zhou JM. Receptor-like kinases in plant innate immunity. J Integr Plant Biol. 2013:55(12):1271-86.

78. Wan J, Zhang X, Neece D, Ramonell KM, Clough S, Kim S, et al. A LysM receptor-like kinase plays a critical role in chitin signaling and fungal resistance in Arabidopsis. Plant Cell. 2008;20(2):471-81.

79. Stacey G, Stacey M, Wan J, Zhang X. LysM receptor-like kinases to improve plant defense response against fungal pathogens. In: U.S. Patent 8,097,771, issued Jan 17, 2012.

80. Narsai R, Wang C, Chen J, Wu J, Shou H, Whelan J. Antagonistic, overlapping and distinct responses to biotic stress in rice (Oryza sativa) and interactions with abiotic stress. BMC Genomics. 2013;14:93. http://www.freepatentsonline. com/8097771.pdf

81. Dóczi R, Brader G, Pettkó-Szandtner A, Rajh I, Djamei A, Pitzschke A, et al. The Arabidopsis mitogen-activated protein kinase kinase MKK3 is upstream of group $C$ mitogen-activated protein kinases and participates in pathogen signaling. Plant Cell. 2007;19(10):3266-79.

82. Wang S, Li M, Dong H, Liu XZ, Bai YJ, Yang H. Sporulation, inoculation methods and pathogenicity of Ustilaginoidea albicans, the cause of white rice false smut in China. J Phytopathol. 2008;156(11-12):755-7.

83. Li R, YU C, Li Y, Lam T, Yiu S, Kristiansen K, et al. SOAP2: an improved ultrafast tool for short read alignment. Bioinformatics. 2009;25(15):1966-7.

84. Benjamini $Y$, Yekutieli $D$. The control of the false discovery rate in multiple testing under dependency. Ann Stat. 2001;29(4):1165-88.

85. Ye J, Fang L, Zheng $H$, Zhang $Y$, Chen J, Zhang Z, et al. WEGO: a web too for plotting GO annotations. Nucleic Acids Res. 2006;34 Suppl 2:W293-7.

86. Kanehisa M, Araki M, Goto S, Hattori M, Hirakawa M, Itoh M, et al. KEGG for linking genomes to life and the environment. Nucleic Acids Res. 2008;36 Suppl 1:D480-4

87. de Hoon M, Imoto S, Nolan J, Miyano S. Open Source Clustering Software. Bioinformatics. 2004;20(9):1453-54.

88. Higo K, Ugawa Y, Iwamoto M, Korenaga T. Plant cis-acting regulatory DNA elements (PLACE) database: 1999. Nucleic Acids Res. 1999;27(1):297-300.

89. Yamamoto YY, Yoshioka Y, Hyakumachi M, Maruyama K, Yamaguchi-Shinozaki K, Tokizawa M, et al. Prediction of transcriptional regulatory elements for plant hormone responses based on microarray data. BMC Plant Biol. 2011:11:39.

90. Livak KJ, Schmittgen TD. Analysis of relative gene expression data using realtime quantitative PCR and the 2 - ${ }^{\Delta \Delta C}$ Method. Methods. 2001:25(4):402-8. 